\title{
Endothelium Modulates Contractile Response to Simvastatin in Rat Aorta
}

\author{
Concepción Pérez-Guerrero*, María Álvarez de Sotomayor, \\ Maria Dolores Herrera and Elisa Marhuenda \\ Department of Pharmacology, Faculty of Pharmacy, University of Seville, Profesor \\ Garcia-Gonzalez s/n, 41012 Seville, Spain. Fax: 34-95-4233765. E-mail: aldesoto@fafar.us.es \\ * Author for correspondence and reprints requests \\ Z. Naturforsch. 55c, 121-124 (2000); received July 22/September 10/1999 \\ HMG-CoA Reductase, Simvastatin, Endothelium, Rat Aorta
}

Simvastatin is an inhibitor of HMG-CoA reductase used in the treatment of hypercholesterolemia. In the present study simvastatin-induced contraction was observed in rat aortic thoracic rings, this effect increased when the endothelium was removed and when NO synthase was blocked by L-NOARG $\left(3 \times 10^{-5} \mathrm{M}\right)$. The contractile effect of simvastatin on intact aortic rings diminished when cyclo-oxygenase was inhibited with indomethacin $\left(10^{-5} \mathrm{M}\right)$. Also in the presence of endothelium, pretreatment with mevalonate $(1 \mathrm{mM})$, the product of HMG$\mathrm{CoA}$ reductase activity, significantly inhibited the contraction. In other experiments carried out on endothelium-removed preparations and in medium containing the calcium antagonist, diltiazem $\left(10^{-5}\right.$ and $\left.10^{-6} \mathrm{M}\right)$, the contraction dose-response curves were significantly reduced and the same happened in the presence of the inhibitor of sarcoplasmic reticulum $\mathrm{Ca}_{-}{ }^{2+}-$ ATPase, cyclopiazonic acid (CPA) $\left(3 \times 10^{-6} \mathrm{M}\right)$.

The results suggest that simvastatin might increase intracellular calcium concentration. This effect could lead to an activation of NO synthase and cyclooxygenase pathways in endothelial cells and to contraction in vascular smooth muscle cells. This rise in $\mathrm{Ca}^{2+}$ concentration could be due to an inhibition of isoprenoid synthesis prevented by mevalonate.

\section{Introduction}

Simvastatin is a drug widely used in the treatment of hypercholesterolemia. This drug is an inhibitor of the rate-determining enzyme in the biosynthesis of cholesterol, 3-hydroxy-3-methylglutaryl-coenzyme A (HMG-CoA) reductase and has proved useful in the reduction of plasma low density lipoprotein (LDL). Clinical trials have demostrated that inhibitors of HMG-CoA reductase decrease cardiovascular-related morbidity and mortality (Vaughan et al., 1996).

In previous studies of our laboratory, we found that another HMG-CoA reductase inhibitor, lovastatin, was able to decrease blood pressure and had vasodilatatory effects in precontracted isolated rat thoracic aorta (Bravo et al., 1998). It has also been demostrated that chronic treatment with simvastatin was able to improve endothelial function in spontaneously hypertensive rats (Álvarez de Sotomayor et al., 1999). In order to elucidate the mechanism of action of simvastatin, the direct effect of this drug was investigated in rat thoracic aortic rings.

\section{Material and Methods}

\section{Experimental procedure}

Wistar male rats $(250-300 \mathrm{~g})$ were killed by a blow on the head. The descending thoracic aorta was rapidly dissected and placed in a modified Krebs-Henseleit solution (PSS), containing (mM): $\mathrm{NaCl} 118, \mathrm{KCl} 4.75, \mathrm{NaHCO}_{3} 25, \mathrm{MgSO}_{4} 1.2$, $\mathrm{CaCl}_{2} 1.8, \mathrm{KH}_{2} \mathrm{PO}_{4} 1.2$ and glucose 11 . After excess fat and connective tissue were removed, the aortas were out cut into $2-3 \mathrm{~mm}$ rings. Aortic rings were mounted under the basal tension of 1 $\mathrm{g}$ in $20 \mathrm{ml}$ organ baths containing PSS and attached to a force-displacement transductor (Harvard UF-1) and the signal was recorded by a Powerlab $^{\circledR}$ data acquisition system (ADInstruments) to measure the contractile force. The tissue bath was maintained at $37{ }^{\circ} \mathrm{C}$ and bubbled with a $95 \%$ $\mathrm{O}_{2}-5 \% \mathrm{CO}_{2}(\mathrm{v} / \mathrm{v})$ gas mixture. In some experiments, the endothelium of the aorta was mechanically removed by gently rubbing the inner surface. The absence of endothelium was confirmed by the absence of relaxing effects of acetylcholine (ACh $10^{-6} \mathrm{M}$ ) in aortic rings previously contracted by noradrenalin (NA $10^{-5} \mathrm{M}$ ). Each preparation was 
allowed to equilibrate for at least $90 \mathrm{~min}$ prior to start of experimental procedures, and during this period the incubation media was changed every $20 \mathrm{~min}$.

Dose-response curves of contraction were obtained by addition of cumulative concentrations of simvastatin $\left(10^{-7}\right.$ to $\left.10^{-4} \mathrm{M}\right)$ at 3 -min intervals in the presence and absence of endothelium. The same experiments were carried out in the presence of $\mathrm{N}$ - $\omega$-nitro-L-arginine (L-NOARG, $\left.3 \times 10^{-5} \mathrm{M}\right)$, indomethacin $\left(10^{-5} \mathrm{M}\right)$, mevalonate $(1 \mathrm{mM})$, diltiazem $\left(10^{-6} \mathrm{M}\right.$ or $\left.10^{-5} \mathrm{M}\right)$ and cyclopiazonic acid $\left(\mathrm{CPA}, 3 \times 10^{-6} \mathrm{M}\right)$ in aortic rings. All results are expressed as a percentage of the maximal contraction of noradrenalin-induced responses.

\section{Drugs}

Indomethacin (1-[p-chlorobenzoyl]-5-methoxy2 -methylindole-3-acetic acid), mevalonate (DL- $\beta$ hydroxy- $\beta$-methyl- $\delta$-valero-lactone), $\mathrm{N}-\omega$-nitro-Larginine $\left(\mathrm{N}^{5}-\right.$ [nitroamidino]-L-2,5-diaminopentanoic acid), diltiazem (cis-(+)-3-(acetyloxy)-5-[2(dimethyl-amino)ethyl]-2,3-dihydro-2-(4-methoxy-phenyl)-1,1-benzothiazepin-4 $(5 \mathrm{H})$ one) hydrochloride, cyclopiazonic acid $\left(\mathrm{C}_{20} \mathrm{H}_{20} \mathrm{~N}_{2} \mathrm{O}_{3}\right)$ from Penicillium cyclopium, acetylcholine $\left(\mathrm{C}_{7} \mathrm{H}_{16} \mathrm{NO}_{2} \mathrm{Cl}\right)$ and noradrenalin (-)-arterenol $\left(\mathrm{C}_{8} \mathrm{H}_{11} \mathrm{NO}_{3} \cdot \mathrm{C}_{4} \mathrm{H}_{6} \mathrm{O}_{6}\right)$ were obtained from Sigma Chemical Co (St. Louis, MO, USA).

Simvastatin (2,2-dimethylbutanoate 1,2,3,7,8,8ahexahydro-3,7-dimethyl-8-[2-tetrahydro-4-hydroxy-6-oxo-2H-pyran-2-yl)ethyl]-1-naphthalenyl),

was generously provided by Merck laboratories (New Jersey, USA). All drugs were dissolved in dimethylsulfoxide (DMSO) except $\mathrm{N}-\omega$-nitro-Larginine and diltiazem which were dissolved in distilled water. The final concentration of DMSO did not significantly affect the results.

\section{Statistical analysis}

Results are expressed as mean \pm SEM of six preparations obtained from different animals. Analysis of variance (ANOVA) followed by the LSD (least significant difference) test were used for statistical analysis. $\mathrm{P}$ values $<0.05$ were considered to indicate a significant difference. Doseresponse slopes were analysed to give the concentration of simvastatin producing $50 \%$ of the maxi- mum contractile response $\left(\mathrm{ED}_{50}\right)$ using a linear regression analysis.

\section{Results and Discussion}

Addition of cumulative concentrations of simvastatin $\left(10^{-7}\right.$ to $\left.10^{-4} \mathrm{M}\right)$ induced dose-dependent contractions in isolated rat thoracic aorta with and without endothelium, reaching maximal tension values of $1.22 \pm 0.08 \mathrm{~g}$ and $1.94 \pm 0.12 \mathrm{~g}$ and the $\mathrm{ED}_{50}$ values were $3.46 \pm 0.56 \times 10^{-5} \mathrm{M}$ and $5.41 \pm$ $0.25 \times 10^{-6} \mathrm{M}$, respectively. In intact aortic rings, preincubation with L-NOARG $\left(3 \times 10^{-5} \mathrm{M}\right)$ significantly potentiated the contractions evoked by simvastatin $\left(\mathrm{ED}_{50}=3.62 \pm 0.27 \times 10^{-6} \mathrm{M}\right)$. However, pretreatment of the aortic rings with indomethacin $\left(10^{-5} \mathrm{M}\right)$ decreased the curve obtained with simvastatin alone underneath the control curve reaching only $30 \%$ of the maximal effect.

In the presence of mevalonate $(1 \mathrm{~mm})$, the product of HMG-CoA reductase activity, simvastatininduced contraction was almost abolished. When the experiments were carried out on endotheliumremoved preparations and in a medium containing diltiazem $\left(10^{-6} \mathrm{M}\right.$ or $\left.10^{-5} \mathrm{M}\right)$, the curve obtained with simvastatin was significantly reduced, yielding a higher effect at the highest dose of diltiazem assayed. Pretreatment with cyclopiazonic acid $(3 \times$ $10^{-6} \mathrm{M}$ ) diminished the contractile effect of simvastatin on endothelium-intact preparations. The percent data are summarized in Table I.

The contractile effect induced by simvastatin in rat aortic thoracic rings increased when the endothelium was removed, showing the involvement of endothelial factors in the mechanism of action of simvastatin. When NO synthase was blocked with L-NOARG, the contraction caused by simvastatin was enhanced, suggesting that NO is released in the presence of simvastatin, opposing its relaxant effect to the contraction. In this way, former experiences have shown that $\mathrm{NO}$ is involved in some actions of statins (Laufs et al., 1998; HernándezPerera et al., 1998; Kaesemeyer et al., 1999). The contractile effect diminished when indomethacin inhibited cyclo-oxygenase, supporting the notion of a partial participation of contracting cyclo-oxygenase-derived factors (endoperoxides and thromboxanes) in this effect. Both results together might be explained by an action of simvastatin in a corvengent point of both, NO synthase and cyclo-oxy- 
Table I. Percentage effect reached in response to simvastatin $\left(10^{-7}-10^{-4} \mathrm{M}\right)$ in aortic rings with $(E(+))$ and without endothelium $(E(-))$. In the absence of L-NOARG, indomethacin (INDO), cyclopiazonic acid (CPA), diltiazem (DIL) and mevalonate (MV). Values are mean \pm SEM of $n=6$ experiments. $* \mathrm{P}<0.05 ; * * \mathrm{P}<0.01 ; * * * \mathrm{P}<0.001$ vs control with endothelium. \#P $<0.05$; \#\#P $<0.01$; \#\#\#P0.001 vs control without endothelium.

\begin{tabular}{|c|c|c|c|c|}
\hline Simvastatin (m) & $10^{-7}$ & $10^{-6}$ & $10^{-5}$ & $10^{-4}$ \\
\hline Control $E(+)$ & $0.7 \pm 0.2$ & $1.7 \pm 1.0$ & $28.7 \pm 6.0$ & $63.6 \pm 7.7$ \\
\hline Control $E(-)$ & $1.2 \pm 0.5$ & $15.1 \pm 4.0$ & $64.8 \pm 5.9 * * *$ & $89.8 \pm 3.8 *$ \\
\hline L-NOARG $\left(3 \times 10^{-5}\right.$ м) $E(+)$ & $0.7 \pm 0.6$ & $17.3 \pm 7.4$ & $76.9 \pm 11.2 * * *$ & $107.9 \pm 9.8 * * *$ \\
\hline INDO $\left(10^{-5} \mathrm{M}\right) E(+)$ & $0.9 \pm 0.2$ & $0.9 \pm 0.3$ & $9.6 \pm 4.4$ & $30.0 \pm 6.6 * *$ \\
\hline $\operatorname{MV}\left(10^{-3}\right.$ м) $E(+)$ & $1.8 \pm 1.1$ & $1.9 \pm 1.1$ & $2.4 \pm 1.0 * *$ & $13.9 \pm 4.5 * * *$ \\
\hline $\mathrm{CPA}\left(3 \times 10^{-5} \mathrm{M}\right) E(-)$ & $1.7 \pm 0.9$ & $4.2 \pm 1.1 \#$ & $18.8 \pm 2.5 \# \#$ & $38.3 \pm 4.3 \# \# \#$ \\
\hline $\mathrm{CPA}\left(3 \times 10^{-6} \mathrm{M}\right) E(-)$ & $0.4 \pm 0.2$ & $0.6 \pm 0.1 \#$ & $12.9 \pm 2.2 \# \# \#$ & $44.7 \pm 6.0 \# \# \#$ \\
\hline DIL $\left(10^{-5}\right.$ M) $E(-)$ & $6.0 \pm 3.0$ & $3.8 \pm 1.7 \#$ & $9.2 \pm 2.2 \# \# \#$ & $23.3 \pm 6.1 \# \# \#$ \\
\hline DIL $\left(10^{-6}\right.$ м $) E(-)$ & $3.1 \pm 2.2$ & $3.3 \pm 1.4 \#$ & $15.2 \pm 4.6 \# \# \#$ & $46.8 \pm 6.8 \# \# \#$ \\
\hline
\end{tabular}

L-NOARG, N- $\omega$-nitro-L-arginine.

INDO, indomethacin.

MV, mevalonate.

CPA, cyclopiazonic acid.

DIL, diltiazem.

$E(+)$, with endothelium.

$E(-)$, without endothelium.

genase pathways, like $\mathrm{Ca}^{2+}$ increment in endothelial cell, necessary for activation of NO synthase (Moncada et al., 1991) and phospholipase $\mathrm{A}_{2}$ (Verbeij et al., 1981), and consequently cyclo-oxygenase. The presence of mevalonate, the metabolic product of HMG-CoA reductase (Goldstein and Brown 1990), almost abolished simvastatin-induced contraction, indicating the involvement of mevalonate pathway. In accordance with our hypothesis, some other reports showed that in vascular smooth muscle cells, simvastatin has been able to increase transiently cytosolic free $\mathrm{Ca}^{2+}$ concentration, being this effect prevented by the presence of mevalonate $(\mathrm{Ng}$ et al., 1994; Escobales et al., 1996).
Diltiazem, a calcium entry antagonist, and cyclopiazonic acid, a $\mathrm{Ca}^{2+}$-ATPase inhibitor, were effective in inhibiting the contractile response to simvastatin, leading us conclude that both: voltageoperated $\mathrm{Ca}^{2+}$ channels and calcium released from these stores are involved in the contractile mechanism of simvastatin. In summary, simvastatin might increase intracellular calcium concentration in both endothelial and vascular smooth muscle cells. This effect lead to an activation of NO synthase and cyclo-oxygenase pathway in endothelial cells and to contraction in vascular smooth muscle cells. 
Álvarez de Sotomayor M., Pérez-Guerrero C., Herrera M. D. and Marhuenda E. (1999), Effects of chronic treatment with simvastatin on endothelial dysfunction in spontancously hypertensive rats. J. Hypertens. 17, $769-776$.

Bravo L., Herrera M. D., Marhuenda E. and PérezGuerrero C. (1998), Cardiovascular effects of lovastatin in normotensive and spontaneously hypertensive rats. Gen. Pharmacol. 30, 331-336.

Escobales N., Castro M., Altieri P. I. and Sanabria, P. (1996), Simvastatin releases $\mathrm{Ca}^{2+}$ from a thapsigarginsensitive pool and inhibits $\mathrm{InsP}_{3}$-depent $\mathrm{Ca}^{2+}$ mobilization in vascular smooth muscle cells. J. Cardiovasc. Pharmacol. 27, 383-391.

Goldstein J. L. and Brown M. S. (1990), Regulation of mevalonate pathway. Nature. 343, 425-430.

Hernández-Perera O., Pérez-Sala D., Navarro-Antolin J., Sánchez-Pascuala R., Hernández G., Díaz C. and Lamas S. (1998), Effects of 3-hydroxy-3-methylglutaryl$\mathrm{CoA}$ reductase inhibitors, atorvastatin and simvastatin, on the expression of endothelin-1 and endothelial nitric oxide synthase in vascular endothelial cells. J. Clin. Invest. 101, 2711-2719.
Kaesemeyer W. H., Caidwell R. B., Huang J. and Caldwell R. W. (1999), Pravastatin sodium activates endothelial nitric oxide synthase independent of its cholesterol-lowering actions. J. Am. Coll. Cardiol. 33, $234-$ 241.

Laufs U., La Fata V., Plutzky J. and Liao J. K. (1998), Upregulation of endothelial nitric oxide synthase by HMG CoA reductase inhibitors. Circulation. 97, 1129-1135.

Moncada S., Palmer R. M. J. and Higg E. A. (1991), Nitric oxide: physiology, pathophysiology and pharmacology. Pharmacol. Rev. 43, 109-142.

Ng. L. L., Davies J. E. and Wojcikiewicz R. J. H. (1994), 3-Hydroxy-3-methylglutaryl Coenzyme A reductase inhibition modulates vasopressin-stimulated $\mathrm{Ca}^{2+}$ responses in rat A 10 vascular smooth muscle cells. Circ. Res. 74, 173-181.

Vaughan C. J., Murphy M. B. and Buckley B. M. (1996), Statins do more than just lower cholesterol. Lancet 348, 1079-1082.

Verbeij H. M., Slothoom A. J. and De Haas G. H. (1981), Structure and function of phospholipase $A_{2}$. Rev. Physiol. Biochem. Pharmacol. 91, 91-203. 